\title{
Representações Sociais do Projeto de Vida entre Adolescentes no Ensino Médio
}

Social Representations of Life Project among Adolescents in High School

Representaciones Sociales del Proyecto de Vida entre Adolescentes en la Enseñanza Media

Maria Quitéria dos Santos

Marcelino, Maria de

Fátima Fernandes Martins

Catão \& Claudia Maria

Pereira de Lima

Universidade

Federal da Paraíba
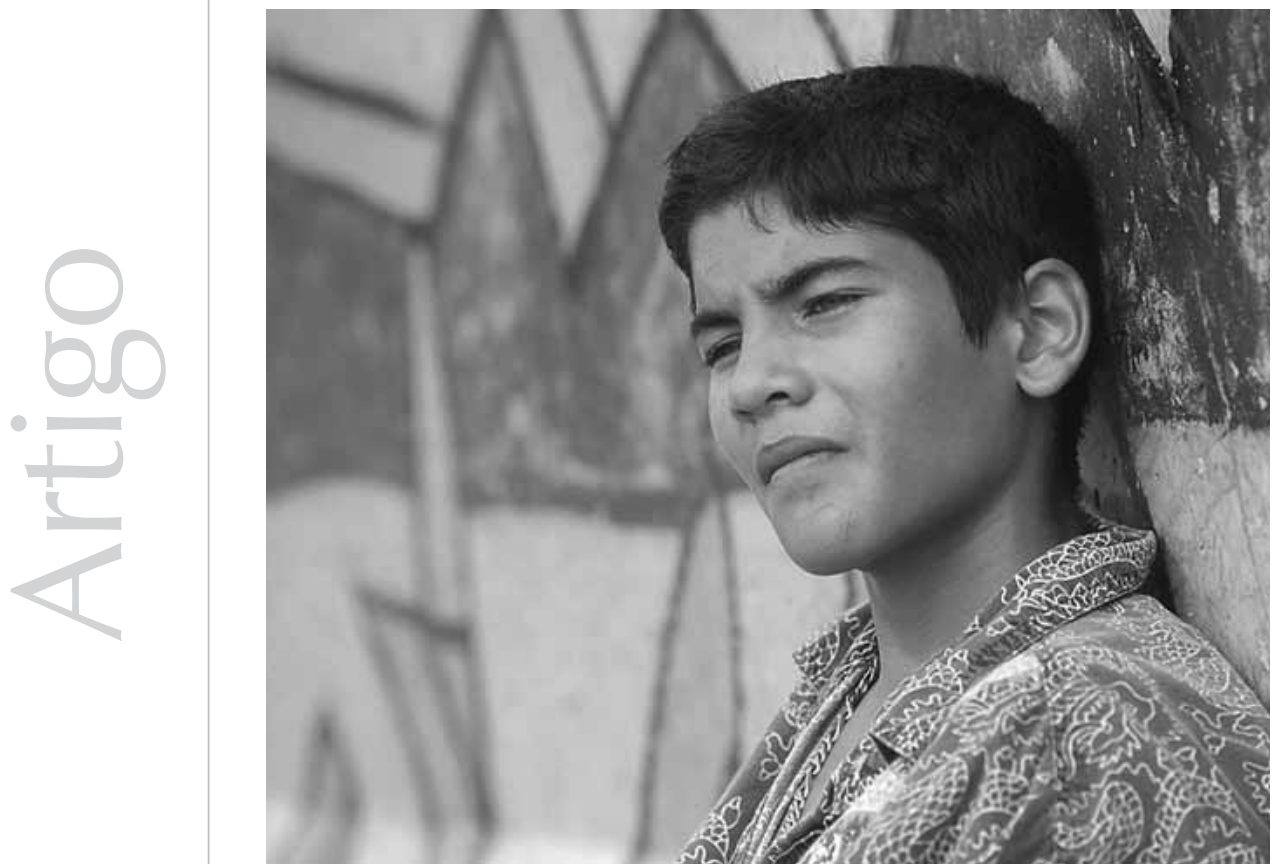
Resumo: Esta pesquisa, da qual participaram 40 adolescentes de ambos os sexos, com idade entre 16 e 19 anos, tem por objetivo comparar as representações sociais dos adolescentes inseridos em diferentes contextos escolares (público e privado) acerca da construção do seu projeto de vida. Foram utilizados questionário semi-aberto para caracterização sociodemográfica e entrevista semi-estruturada para captura das representações. Os dados foram submetidos à análise de conteúdo, com apoio do programa ALCESTE, sistema automático de análise de dados textuais. Os dados obtidos demonstraram representações consensuais a respeito do projeto de vida, como desejos, metas, previsões e estratégias. Entretanto, os alunos da escola pública objetivaram suas representações na necessidade de inclusão social e na melhoria de vida, enquanto os da escola privada objetivaram suas representações nas dificuldades relacionadas à escolha da profissão. Conclui-se haver a necessidade de políticas públicas que possibilitem, nesses diferentes contextos escolares, condições semelhantes para a construção de projetos de vida.

Palavras-chave: Adolescentes. Projeto de vida. Representações sociais.

Abstract: The objective of this research was to compare the social representations of adolescents in different school contexts (public and private) about the construction of their project of life. It involved 40 adolescents, male and female, aged 16 to 19 years. A semi-structured questionnaire for socio-demographic characterization and a semi-structured interview were used as instruments. The data were submitted to content analysis, with the support of the programme ALCESTE, automatic system of textual data analysis. The data obtained showed consensual representations about the project of life, as desires, marks, previsions and strategies. Nevertheless, the students of the public schools centered their representations in the necessity of social inclusion and improvement of life, while the pupils of private school objectified their representations on the difficulty related to the choice of the profession. It follows that there is the necessity of public politicies that allow similar conditions for the construction of projects of life in these different school contexts.

Keywords: Adolescents. Life project. Social representations.

Resumen: Esta pesquisa, de la cual participaron 40 adolescentes de ambos los sexos, con edad entre 16 y 19 años, tiene por objetivo comparar las representaciones sociales de los adolescentes inseridos en diferentes contextos escolares (público y privado) acerca de la construcción de su proyecto de vida. Fueron utilizados cuestionarios semi-abiertos para caracterización sociodemográfica y entrevista semi-estructurada para apresamiento de las representaciones. Los datos fueron sometidos al análisis de contenido, con apoyo del programa ALCESTE, sistema automático de análisis de datos textuales. Los datos logrados demostraron representaciones consensuales a respeto del proyecto de vida, como deseos, metas, previsiones y estrategias. Mientras, los alumnos de la escuela pública objetivaron sus representaciones en la necesidad de inclusión social y en la mejora de vida, mientras los de la escuela privada objetivaron sus representaciones en las dificultades relacionadas a la elección de la profesión. Se concluye haber la necesidad de políticas públicas que posibiliten, en esos diferentes contextos escolares, condiciones semejantes para la construcción de proyectos de vida.

Palabras clave: Adolescentes. Proyecto de ida. Representaciones sociales.

A adolescência é um momento em que escolhas são feitas e projetos começam a ser construídos e não consiste, necessariamente, em um momento de crise. Nesses projetos, está contida a visão que o adolescente tem de si mesmo, das suas qualidades e daquilo que deseja alcançar, e "essa visão de futuro está ligada às suas vivências e experiências anteriores e às relações estabelecidas até então na sua história" (Serrão \& Baleeiro, 1999, p. 278). Nessa ótica, a construção do projeto de vida é um processo de desenvolvimento pessoal/social. Considerase, assim, que o adolescente esteja preparado para iniciar essa construção após ser capaz de formar sua identidade, compartilhá-la com o grupo e comunicar sonhos, desejos, planos, metas. É nesse momento que ele pode ingressar em uma nova etapa de vida.

Inserida na realidade social, a escola é espaço de construção da subjetividade e, assim sendo, é também importante lugar para a construção do projeto de vida, especialmente no ensino médio, nível de escolaridade que compreende a fase da vida em que se intensifica essa construção devido à pressão sofrida pelos adolescentes para que escolham (ou ao menos atinjam) uma profissão. Como toda e qualquer instituição social, a existência 
da escola não pode ser considerada de forma autônoma e independente da realidade histórico-social, pois ela é parte integrante e inseparável do conjunto dos demais fenômenos que compõem a totalidade social (Franco, 1991). Considerando a escola uma das dimensões da totalidade social em que os adolescentes constroem seus projetos de vida, pode ser vista como instituição, no modelo preconizado por Lourau e Ardoino (1994), que reproduz e transforma o modelo social onde se insere e as relações sociais que nela se estabelecem. Essa postura é adotada também por Franco (1991), que considera a escola ao mesmo tempo reprodução/ transformação da realidade histórico-social existente.

Dessa forma, evidencia-se a necessidade de pesquisas que reflitam sobre as representações sociais dos adolescentes relativas à construção dos seus projetos de vida, como conhecimento que poderá contribuir para as suas práticas enquanto futuros cidadãos e profissionais. O presente estudo, ao focalizar os contextos escolares como configuradores de subjetividades, do desenvolvimento da cidadania e da construção do projeto de vida, propõe-se a capturar o conhecimento do cotidiano e a apoiar intervenções no âmbito educacional. Inserida nesse contexto, esta pesquisa objetiva comparar as representações sociais (RS) acerca da construção do projeto de vida dos adolescentes do ensino médio de uma escola pública e de uma escola privada situadas na cidade de João Pessoa, PB.

\section{Adolescência e Projeto de Vida Uma Construção Psico- Sociohistórica}

A concepção naturalista e universal da adolescência, imputada por algumas correntes teóricas e compartilhada pela Psicologia, foi incorporada pela cultura ocidental e assimilada no senso comum, pressupõe que já exista uma crise no adolescente, marcada por tormentos e conturbações relacionadas à emergência da sexualidade. Essa concepção sobre a adolescência está fortemente ligada a estigmas e a estereótipos (Ozella, 2002). A Psicologia convencional insiste em negligenciar a inserção histórica do adolescente e suas condições de vida objetiva/subjetiva, supondo uma igualdade de oportunidades para todos esses jovens, o que dissimula e oculta desigualdades sociais e coloca no próprio jovem toda a responsabilidade de suas ações (Bock, Furtado, \& Teixeira, 1996; Catão, 2001b; Clímaco, 1991).

A concepção da adolescência como uma configuração psico-sociohistórica considera que só é possível compreender qualquer fato a partir de sua inserção na totalidade em que esse fato foi produzido. Assim sendo, a adolescência precisa ser compreendida nessa inserção. Bock et al., (1996) refletem que não existe a adolescência, mas sim, adolescentes. Isso significa que falar de adolescência é falar das condições sociais que constroem uma determinada adolescência. A adolescência não se configura em um período natural do desenvolvimento, mas em um momento significado e interpretado pelos sujeitos. Tal concepção percebe o adolescente como um ser ativo, social e histórico, que produz histórica e coletivamente a si próprio e à sociedade e é por ela produzido. (Bock et al., 1996, Bock, Marchina, \& Furtado, 2001; Catão, 2001b; Sawaia, 2006; Vigotski, 1999, 2000). Definir adolescência, portanto, é capturar significações e interpretar a realidade. O adolescente, concebido como ser psicosociohistórico, expressa, através da linguagem, os componentes afetivos, históricos e sociais do seu pensamento sobre seu projeto de vida. 
Catão (2001b) define o projeto de vida como a intenção de transformação da realidade, orientado por uma representação do sentido dessa transformação, em que são consideradas as condições reais na relação entre passado e presente na perspectiva de futuro.
Catão (2001b) define o projeto de vida como a intenção de transformação da realidade, orientado por uma representação do sentido dessa transformação, em que são consideradas as condições reais na relação entre passado e presente na perspectiva de futuro. Como perspectiva de futuro, reflete a autora, que o projeto é vivenciado desde a infância, quando o indivíduo apreende sua condição social por meio da família e da comunidade. Contudo, essa construção não se limita apenas às condições objetivas de vida, mas é caracterizada na dialética entre a subjetividade e a objetividade, pois é através da reflexão crítica de suas vivências que os indivíduos vêem possibilidade/impossibilidades de superação de uma determinada realidade no futuro. A construção do projeto de vida é uma configuração humana do ser cidadão, sujeito de sua história individual/social, uma criação analítica, crítica e articulada.

O projeto de vida, como reflete Catão (2001a, 2007), é processo e produto da práxis, e, como uma organização multidimensional psicosociohistórica, envolve dimensões articuladas entre si: socioafetiva, sociocognitiva e espaçotemporal. Tais dimensões se configuram pelo estabelecimento do diálogo entre a mente e a produção de idéias, pelo discurso interior na mediação com o mundo exterior, pela configuração dos afetos, das paixões, da ética, pela potência da ação humana, e não como propriedade do sujeito, mas como possibilidade de vir a ser, enquanto capacidade de ser afetado pelo outro (Catão, 2007; Sawaia, 2006; Vigotski, 2000). A dimensão espaço-temporal do projeto de vida é o agora cotidiano, por ser este a objetivação da interface entre o passado, presente e futuro e entre as duas esferas da vida cotidiana: a pública e a privada (Catão, 2007).

\section{Representações Sociais}

A área educacional é um campo privilegiado para se observar a construção, a evolução e a transformação das representações sociais. O sistema escolar sempre foi configurado pelos grupos que nele ocupam diferentes posições. Essas configurações não são proporcionais entre si em razão das desigualdades sociais existentes, uma vez que o referido sistema reproduz as relações estabelecidas na sociedade em geral.

Referindo-se ao fenômeno da produção de sentidos, comum a todas as sociedades, as representações sociais são definidas por Jodelet (2001) como uma modalidade de conhecimento socialmente elaborada e partilhada, com um objetivo prático, que contribui para a construção de uma realidade comum a um conjunto social. Essas representações consistem em um conjunto de conceitos, proposições e explicações criadas na vida quotidiana no decurso da comunicação individual. Trata-se, portanto, de um saber prático que liga um sujeito pensante a um objeto (Moscovici, 1984).

Como fenômeno sociocognitivo-afetivo, envolve a pertença social dos indivíduos, nos níveis das implicações afetivas e normativas, das interiorizações de experiências práticas, dos modelos de condutas e dos pensamentos transmitidos pela cultura (Moscovici, 2003); por isso, seu estudo constitui uma contribuição incontestável para a abordagem da vida mental individual e coletiva. Desse ponto de vista, as representações sociais são abordadas concomitantemente como produto e processo de uma atividade de apropriação da realidade exterior ao pensamento e de elaboração psicológica e social dessa realidade (Jodelet, 2001). 
Partindo do pressuposto de que cada sujeito não é isolado no mundo, considera-se a existência de uma intersubjetividade, um espaço comum, ou convencional, de representação possível. Entende-se que, numa dada população, os indivíduos partilham mais ou menos os mesmos objetos subjetivos, o que lhes permite comunicar-se e agir em comum (Catão \& Coutinho, 2003). De acordo com as autoras, a representação é social por ser construída coletivamente como um produto das interações e dos fenômenos de comunicação em uma dada sociedade e no interior de um grupo de pertença; reflete, portanto, o contexto ideológico, econômico e social desse grupo, através do qual são perpassados seus conhecimentos e significados, práticas e comunicações, problemas, estratégias e aspirações. Por isso, as representações sociais se colocam, simultaneamente, como individuais e sociais.

A importância deste estudo para a teoria das representações sociais pode ser verificada na objetivação desse referencial na análise da cultura e na possibilidade de intervenção transformadora, em nível da construção do projeto de vida de adolescentes em contextos de escolas públicas e privadas. Reafirmam-se, com a pesquisa realizada, as representações sociais como sistema de interpretação da relação dos indivíduos consigo, com os outros e com o mundo bem como com os significados do projeto de vida, construtores desse projeto. Diante do exposto, considerase a referida teoria um referencial adequado para a comparação das representações sociais de diferentes grupos de pertença a respeito de um determinado objeto que faz parte de sua realidade, como foi o caso deste estudo, focado na comparação das representações sociais de dois grupos de adolescentes (alunos de uma escola pública e alunos de uma escola particular) a respeito de seus projetos de vida.

\section{Método}

O presente estudo, aprovado pelo Comitê de Ética em Pesquisa do Centro de Ciências da Saúde da Universidade Federal da Paraíba, protocolo n.126/05, foi realizado com adolescentes em contexto de escola pública e de escola privada do Município de João Pessoa, capital do Estado da Paraíba. O contato com as instituições participantes foi feito inicialmente através da Clínica Escola de Psicologia da mesma universidade. Uma vez estabelecido o contato, verificou-se a disposição dos diretores das instituições em permitir que os alunos participassem de forma voluntária da pesquisa.

\section{Participantes}

Procedeu-se à escolha dos adolescentes de acordo com os seguintes critérios: estar cursando o $3^{\text {o }}$ ano do ensino médio, ter cursado o ensino médio na mesma instituição e na mesma rede (pública ou privada), sexo, aceitação e disponibilidade de participação. Participaram desta pesquisa 40 adolescentes, distribuídos em dois grupos: grupo A (adolescentes que freqüentam uma escola pública) e grupo B (adolescentes que freqüentam uma escola privada), sendo 20 de cada grupo, emparelhados por sexo e selecionados para a entrevista mediante avaliação do questionário sociodemográfico aplicado em cada turma do ensino médio das escolas pesquisadas. As idades entre os adolescentes da escola pública variam entre 16 e 19 anos; os adolescentes da escola privada, por sua vez, têm entre 16 e 17 anos.

\section{Instrumentos e procedimentos}

Em um primeiro momento, os dados foram obtidos através da aplicação de um 
questionário semi-aberto para caracterização sociodemográfica e seleção dos participantes da entrevista. Posteriormente e mediante essa caracterização, foram realizadas, de forma individual, as entrevistas semiestruturadas, com aplicação do seguinte roteiro indutor: "O que você entende por projeto de vida?, Para você, o que é ter um projeto de vida? e Qual o seu projeto de vida?" Na escola pública, as entrevistas foram realizadas na sala dos professores. $\mathrm{Na}$ escola particular, em uma sala de estudos. Em ambos os ambientes, permaneciam apenas o participante e a pesquisadora. $\mathrm{Na}$ oportunidade, explicitavam-se os objetivos da pesquisa e a necessidade do uso do gravador. Foram-Ihes garantidos o anonimato e a confidencialidade das respostas, indicando que estas seriam analisadas em conjunto.

\section{Análise dos dados}

Optou-se pela técnica de análise de conteúdo categorial temática (Bardin, 2002; Vala, 1994) para compreender e inferir novos conhecimentos a partir dos relatos dos sujeitos. Os dados foram analisados com o auxílio do software ALCESTE-sistema automático de análise de dados textuais (Reinert, 1997). A análise de conteúdo tem por objetivo a compreensão crítica do sentido das comunicações, do seu conteúdo manifesto e/ou latente e das significações explícitas e/ou ocultas. O primeiro momento necessário à análise é a descrição que trata da captura das significações e da enumeração das características do texto, resumida após tratamento. O momento analítico conclusivo é a interpretação das significações e das características do texto. Não é a descrição, mas a inferência, a intenção da análise de conteúdo, que permite a passagem explícita e controlada da descrição à interpretação e toma como referencial de análise o quadro teórico sobre o qual o estudo está sendo construído. Aqui se trabalha com as referências conceituais da teoria das representações sociais e com a configuração psico-sociohistórica da adolescência e do projeto de vida.

O corpus geral do presente estudo foi composto pelo corpus I - constituído pelas entrevistas dos alunos da escola pública - e corpus II - configurado pelas entrevistas dos alunos da escola privada. O plano de análise dos dados aplicado neste estudo foi desenvolvido de acordo com a organização dos seguintes momentos: configuração do referencial teórico conceitual de análise, constituição do corpus e leitura flutuante, efetuação da análise, categorização dos dados, leitura em profundidade dos dados analisados, apresentação e interpretação dos resultados.

\section{Resultados e Discussão}

A análise realizada aponta três classes relacionadas entre si, nas quais emergem os significados do projeto de vida, configurados pelos adolescentes em contexto de escola pública e adolescentes em contexto de escola privada. Nos dois grupos, foi capturada a classe "concepções do projeto de vida". A classe "inclusão social e melhoria de vida" emerge apenas no grupo da escola pública, e a classe "dificuldades na construção do projeto de vida" emerge apenas no grupo da escola privada. As classes identificadas e quantificadas em termos de UCE (unidades de contexto elementar) podem ser observadas na Tabela I. 
Tabela 1. Distribuição das unidades de contexto elementar (UCE) do projeto de vida, apreendidas pela entrevista de adolescentes da escola pública e da escola privada.

\begin{tabular}{|c|c|c|c|c|}
\hline \multirow{2}{*}{ Classes } & \multicolumn{2}{|c|}{$\begin{array}{l}\text { Escola Pública } \\
\text { UCE Entrevista }\end{array}$} & \multicolumn{2}{|c|}{$\begin{array}{l}\text { Escola Privada } \\
\text { UCE Entrevista }\end{array}$} \\
\hline & $(\mathrm{f})$ & $\%$ & (f) & $\%$ \\
\hline $\begin{array}{l}\text { I - Concepções do } \\
\text { projeto de vida } \\
\text { II - Inclusão social e }\end{array}$ & 31 & 65,9 & 40 & 70,2 \\
\hline $\begin{array}{l}\text { melhoria de vida } \\
\text { III - Dificuldades na construção }\end{array}$ & 16 & 34,1 & - & - \\
\hline do projeto de vida & - & - & 17 & 29,8 \\
\hline Total & 47 & 100.00 & 57 & 100.00 \\
\hline
\end{tabular}

Observa-se que, em ambos os grupos, houve o predomínio de UCE na classe I (concepções do projeto de vida), com $65,9 \%$ no grupo da escola pública e $70,2 \%$ no grupo da escola particular. Na classe II, inclusão social e melhoria de vida, exclusiva do grupo da escola pública, figuram $34,1 \%$ das UCE. Entre os alunos da escola privada, emergiu a classe dificuldades na construção, sendo a porcentagem de ocorrência das UCE de 29,8\%. Os conteúdos sistematizados na forma das subclasses existentes em cada classe apresentaram diferenças nos dois grupos de participantes, conforme se pode observar na Tabela II.

Tabela 2. A multidimensionalidade do sentido do projeto de vida.

\begin{tabular}{|c|c|c|}
\hline \multirow[t]{2}{*}{ Classes/ Campos Contextuais } & \multicolumn{2}{|c|}{ Participantes da } \\
\hline & Escola Pública & Escola Privada \\
\hline \multicolumn{3}{|l|}{ I - Concepções do projeto de vida } \\
\hline Desejos, metas, previsões, estratégias & $x$ & $X$ \\
\hline Educação, trabalho, família & $x$ & $x$ \\
\hline Essencial ao longo da vida & $x$ & $x$ \\
\hline \multicolumn{3}{|l|}{ II - Inclusão social e melhoria de vida } \\
\hline \multicolumn{3}{|l|}{ Oportunidade de inclusão social e } \\
\hline melhoria de vida & $\mathrm{X}$ & $\ldots$ \\
\hline Ascensão social via escolarização & $x$ & $\ldots$ \\
\hline Auto/hetero ajuda na construção & $x$ & $\ldots$ \\
\hline Possibilidades/impossibilidades de realização & $x$ & $\ldots$ \\
\hline \multicolumn{3}{|l|}{ III - Dificuldades na construção do projeto de vida } \\
\hline Práticas institucionais & $\ldots$. & $X$ \\
\hline Complexidade da construção & $\ldots$ & $x$ \\
\hline Imaturidade & $\ldots$ & $x$ \\
\hline Insuficiência do esforço pessoal & $\ldots$ & $x$ \\
\hline Dificuldades de decisão & $\ldots$ & $x$ \\
\hline Pressão social relacionada à série & $\ldots$ & $x$ \\
\hline
\end{tabular}

$\mathbf{X}=$ Participação na classe/campo contextual

..... = Não participação na classe/campo contextual 
"É você ter tudo certo na sua

cabeça, o que você quer da sua vida, como você vai conseguir as coisas... então você vai é, como

é, prevendo o futuro" (GB).

\section{Concepções do projeto de vida}

Nessa classe ambos os grupos de adolescentes apresentaram representações semelhantes sobre as concepções desse projeto. O projeto de vida figura como um conjunto de desejos que se pretende realizar e como uma série de planos e etapas a serem vencidas rumo ao ideal que se tem, com vistas à organização e à orientação do próprio futuro: "Eu acho que é eu ir em busca daquilo que eu desejo, daquilo que eu procuro" (GA); "O que você quer realmente pra sua vida no futuro" (GB); "São etapas que eu poderia elaborar pra tentar alcançar coisas, metas" (GA); "São planos que eu devo fazer para que sejam concretizados no meu futuro..) ter um projeto de vida é ter um ponto onde você quer chegar" (GB); "É uma forma de a gente estruturar nosso futuro" (GA); "Pra qualquer que seja a direção que você quer levar sua vida, você tem que ter um objetivo pra você trabalhar e chegar até ele" (GB); "É você ter tudo certo na sua cabeça, o que você quer da sua vida, como você vai conseguir as coisas... então você vai é, como é, prevendo o futuro" (GB).

Por um lado, o projeto de vida é configurado como uma ação de transformação do real movida pelo sentido dessa transformação, como uma escolha no presente para a vida no futuro: "Acho que é eu ir em busca daquilo que eu desejo" (adolescente, GA). Por outro lado, o projeto de vida é objetivado em construir e estruturar planos, o que implica desenvolver estratégias para o alcance dos objetivos que se tem: "São planos que eu devo fazer para que sejam concretizados no futuro" (adolescente, GB). Castoriadis (1985), em seu livro A Instituição Imaginária da Sociedade, reflete que é preciso não confundir projeto de vida com plano ou programa. O plano corresponde ao momento técnico de uma atividade, aos meios e às condições objetivas; o projeto está relacionado a um significado de si próprio, de mundo, de si próprio no mundo, a uma práxis do cotidiano com foco no futuro e a uma autonomia do sujeito em constante reflexão e transformação na construção de si próprio e da vida.

O projeto de vida descrito por esses adolescentes está sempre relacionado com a tríade educação/trabalho/ família. Essa tríade, sempre indissociável, compõe uma subclasse que se evidencia nestas falas: "Me formar, dar esse orgulho pra meus pais"; "Trabalhar, me formar, pra me estabelecer financeiramente e criar uma família" (adolescentes, GA); "Me formar, depois casar e ter filhos"; "Meu projeto de vida é ter uma profissão, ter uma família, seguir meus sonhos" (adolescentes, GB).

Os adolescentes consideram a educação formal muito importante para a consecução de um trabalho, e, por conseguinte, da estabilidade financeira necessária à formação e à manutenção de uma família. A formação acadêmica figura como via de acesso a uma profissão e a um futuro melhor. A relação educação/trabalho/família e o papel da educação na preparação para o trabalho ao longo do século XX e XX configuraram-se pelo modelo do capitalismo industrial, colocando como uma das principais funções da escola a reprodução das divisões do trabalho e das relações de trabalho do modelo social vigente.

A construção do projeto de vida é apropriada pelos adolescentes de forma positiva e aproximativa, como um sentido que dá sentido à vida e ao próprio sujeito. O projeto é tido como essencial e inerente ao longo da vida: "Eu acho que pra tudo hoje que a gente analisar, pensar, falar, tudo precisa desse projeto" (adolescente, GA); sujeito e projeto de vida como uma unidade objetiva/subjetiva: "O diálogo da mente com a produção de 
idéias sobre si e sobre o mundo, o discurso interior na mediação com o mundo exterior é o agora cotidiano, por ser a objetivação da interface entre o passado, presente e futuro" (Catão, 2007, p. 77 ); "Todo mundo tem que ter um projeto de vida. Quem não tem, quem não planeja como vai ser futuramente, eu acho que é uma pessoa, venhamos e convenhamos, sem futuro, né?" (adolescente, GB).

\section{O projeto de vida como oportunidade de inclusão social e melhoria de vida}

Os conteúdos correspondentes a essa classe emergiram apenas nos discursos dos participantes da escola pública (GA). A construção do projeto de vida configurase como um processo de viabilização da inclusão social, uma oportunidade de estar na sociedade, ter um lugar social, ou seja, participar, ser incluído socialmente. Em um contexto de exclusão, marcado pela desigualdade social e desrespeito às diferenças, ser incluído socialmente implica melhores condições de vida para si mesmo e para o outro: "Melhorar a nossa vida, melhorar a vida das outras pessoas também" (adolescente, GA), é a possibilidade de transformação do presente e elaboração de um futuro melhor; "Construir uma boa vida" (adolescente, GA), e, para isso, é necessário "aproveitar todas as oportunidades que surgem para mim agora" (adolescente, GA). Observa-se, da parte dos adolescentes em contexto de escola pública, um posicionamento favorável à construção do projeto de vida como possibilidade de inclusão social, um sentido de aproximação que potencializa o sujeito para a vida. Reflete-se sobre a intensidade dessa classe como via histórica das condições de vida dessa população:
Ter um projeto de vida eu acho que, assim, é uma forma de você tá na sociedade, você se relacionar com as pessoas... é você ser reconhecido em qualquer lugar,... é aproveitar todas as oportunidades que surgir pra mim agora... pra melhorar nossa vida, melhorar a vida das outras pessoas também... é você ter, assim, uma boa vida. Construir uma boa vida. (GA)

A intenção de transformar a realidade é sempre voltada para melhorá-la, o que pode ser observado nas falas dos adolescentes que relacionam o projeto de vida à ascensão social via escolarização. O ser "alguém na vida" ou o ser um "Zé ninguém" vai depender daquilo que foi logrado em termos de estudos, ou de educação formal:

Estudar muito pra ser alguém na vida, né? Porque sem o estudo não somos nada. Sem estudar, somos fracos... eu tenho que estudar hoje pra no futuro chegar a conseguir esse projeto... estudar pra quando chegar na frente, ser alguém na vida, porque, hoje em dia, se você não tiver estudo, você é considerado um Zé ninguém. (GA)

Conseguir ou alcançar aquilo que se projetou, ser alguém, ser reconhecido, incluído, ter alguma importância na vida, tudo isso irá depender dos estudos, na visão desses adolescentes. Observa-se a relação estabelecida por esses jovens entre a escolarização e a construção do projeto de vida. Tal pensamento se ancora no mito da mobilidade social ascendente, alimentado pelo modelo capitalista, em que, tendose o mérito individual de lograr êxito, nesse caso academicamente, a ascensão social viria como conseqüência, quase que automaticamente. Entretanto, nas falas dos adolescentes, emergem alguns comentários sobre esse mérito individual na construção do projeto de vida, e questionam se essa construção depende da individualidade ou da alteridade: 
Então isso depende de você, porque você tem um projeto de vida, você tem que lutar com todos, unhas e dentes, pra conseguir tudo que você quer; ... eu acho que depende de você, sim, mas nem sempre. Vários aspectos depende do seu próximo. (adolescentes, GA)

Observa-se o papel do indivíduo e o papel da sociedade nessa construção. Trata-se, pois, de uma construção que se dá entre o "eu" e o "outro", entre o indivíduo e a sociedade, e essa construção não se limita apenas às condições objetivas de vida, mas caracterizase na dialética entre a subjetividade e a objetividade, pois é através da reflexão crítica de suas vivências que os indivíduos vêem possibilidade/impossibilidades de superação de uma determinada realidade no futuro.

Os participantes desse grupo tratam da construção do projeto de vida em termos de possibilidades e impossibilidades, considerando as condições reais para tal construção,

porque muita gente faz projetos e mais projetos e não consegue realizar... eu acho assim que, você passou no vestibular, tudo bem, mas se você for analisar quantas pessoas tem fora, tentando entrar, são muitas. $E$ às vezes não tem aquele estudo essencial, necessário pra passar no vestibular.

(adolescentes, GA)

Observa-se a consideração das dificuldades para a concretização do projeto de vida. Diante do vestibular, a insegurança em termos dos conhecimentos que se conseguiu apreender. Considera-se que a frustração pode ser iminente, o que torna complicada a elaboração do projeto: "É complicado ter planos pro futuro, se não me formar, que isso também pode ser, é, uma constante... se por acaso eu não conseguir passar no vestibular, aí tem que parar de estudar" (adolescentes, GA).
Verifica-se, nessas falas, o receio de que a possibilidade de não ingressar no nível superior se torne realidade. O acesso à universidade representaria a chance de continuidade da construção do projeto de vida. A partir do projeto de entrar na universidade, poderiam ser desenvolvidos novos projetos. A não-realização desse primeiro implicaria não conseguir elaborar novos projetos. Evidencia-se também o caráter dinâmico da construção do projeto de vida, que compreende a transformação constante, o contínuo "fazer outro projeto".

\section{Dificuldades na construção do projeto de vida}

Essa classe emergiu nos discursos dos participantes da escola privada (GB). A construção do projeto de vida é, para eles, algo difícil sob diversos aspectos. Por um lado, apontam práticas institucionais que consideram desfavoráveis à construção do projeto de vida; por outro, falam sobre si, como se vêem, como se interpretam, analisam os significados sobre si como dificuldades e impedimentos no processo de construção do projeto de vida:

Desde pequena, a gente cresce com as
amizades, tudo direitinho; então, querendo
ou não, não é concorrência, é um ajudando
o outro, né... a gente sempre se escorando,
vai se escorando. Eu acho que pra mim seria
melhor eu, pelo menos no terceiro ano,
ter ido pra outro colégio... com relação a
estudo, é muito diferente, não vou mentir,
até com relação às filas. (adolescente, GB)

Observa-se, nessas falas, uma reflexão crítica no sentido de superação de determinada realidade na escola. As práticas das "escoras" no outro, da não competitividade e da "relação de ajuda" são postas como práticas da escola e comparadas à vida fora da escola e à concorrência no vestibular, consideradas 
desfavoráveis para a construção do projeto de vida pelos adolescentes. Tais práticas seriam superadas através da mudança de escola: "Eu acho que pra mim seria melhor eu, pelo menos no terceiro ano, ter ido pra outro colégio". Por força da mudança de instituição, e não de atitude, é que tais "escoras" poderiam ser abandonadas, em prol de um melhor desempenho.

A construção do projeto de vida é vista pelos adolescentes em contexto de escola privada como uma tarefa complicada e complexa devido aos difíceis e diversos aspectos que a configuram. Essa visão se verifica nas seguintes falas: "É complicado pra gente saber cada profissão... aí, quando é pra fazer, é muito complicado... com relação a estudo, eu acho que fica mais complicado" (adolescentes, GB). Os adolescentes relacionam a complexidade da construção do projeto de vida à complexidade da construção de si, falam da falta de maturidade necessária, percebem-se como imaturos diante da responsabilidade que demanda essa construção: "É uma responsabilidade muito grande que tá na minha frente, e eu não consigo pegar... eu ainda me acho com uma cabeça muito pequena com relação a isso. Eu tenho que crescer, não é verdade?" (adolescentes, GB).

O esforço pessoal é considerado imprescindível para o alcance dos objetivos. Apesar de eles reconhecerem a existência desse esforço, não o consideram suficiente:

Eu me esforço bastante, mas não o bastante pra passar pra o que eu quero"; "Sei que eu tenho que me esforçar, eu sei que eu tenho que estudar, mas eu vou deixando o dia passar, e quando eu vejo, já tá esse mês todinho... (adolescentes, GB)

O ser ativo e a tomada de consciência dessa necessidade é posta pelos adolescentes como imprescindível na construção do projeto. Entre o ideal e o real, entre o que se deseja e a realidade objetiva, os participantes situam as dificuldades em decidir entre aquilo que se quer e aquilo que se considera possível conseguir. Tais dificuldades na tomada de decisão figuram em falas como:

Eu sei o que eu quero, mas não sei como conseguir, então, pelo fato de eu não saber como conseguir, eu fico indecisa... eu não sei o que vou fazer se eu não passar pra Medicina. É o que eu quero, mas não sei se vou passar, então eu tô pensando em outras coisas. (adolescentes, GB)

Saber o que quer, acompanhar os conteúdos, passar no vestibular, são cobranças percebidas pelos participantes nesse período de conclusão do ensino médio. A pressão social nesse direcionamento, segundo os mesmos, está relacionada à série que estão cursando. Falas como essas configuram a subclasse: "O terceiro ano é bem mais puxado do que eu imaginava... esse ano principalmente, além do estudo, a cobrança é maior" (adolescentes, GB).

Todas essas questões configuram a complexidade atribuída à construção do projeto de vida pelos adolescentes da escola privada. As dificuldades são objetivadas de várias formas: das práticas institucionais à construção de si, objetivada em torno do sentimento de imaturidade frente à grande responsabilidade da escolha profissional, do esforço pessoal, que parece não ser suficiente para o alcance dos objetivos e das dificuldades de decisão ante a pressão social exercida sobre os jovens nesse sentido.

Adolescentes são sujeitos e, ao mesmo tempo, objeto da construção de projetos de vida em contextos escolares diferenciados, que são o público e o privado. Em ambientes marcados atualmente por diferenças 
estruturais e sociais, esses espaços são alvo de discriminação pelo senso comum, em termos de qualidade dos serviços prestados e, em conseqüência, discriminam-se suas clientelas como as que terão ou não acesso a um ensino de qualidade, as que terão ou não acesso à universidade e a uma colocação no mercado de trabalho.

Configurar as representações sociais do projeto de vida significa ao mesmo tempo construir a sua realidade social, suas condições de produção e de circulação e as experiências vividas pelos grupos na relação com esse projeto, o que provoca a necessidade contínua de reflexões sobre a história e a gênese dos significados do projeto de vida elaborados pelos adolescentes em contextos escolares diferenciados. Admite-se que as representações sociais se configuram em três dimensões: informação, atitude ou afetos e campo representacional ou imagem, e que essa tridimensionalidade varia de grupo para grupo em função do grau de assimilação das dimensões relativas ao objeto representacional (Moscovici, 1961). Evidencia-se, neste estudo, a tridimensionalidade das representações sociais do projeto de vida, e observa-se que os dois grupos de adolescentes apresentam conhecimentos/informações semelhantes ao elaborarem as concepções do projeto de vida como um conjunto de desejos, metas, previsões e estratégias, entendidas como algo essencial ao longo da vida. Ao mesmo tempo, são capturadas organizações diferenciadas de conhecimentos entre os dois grupos, quando se referem à construção desses projetos. Nos adolescentes em contexto escolar público, emerge o conhecimento elaborado sobre projeto de vida como oportunidade, pressuposto para inclusão social e melhoria de vida, remetendo à possibilidade de ascensão social via escolarização. Em contrapartida, nos adolescentes em contexto de escola privada, configura-se uma organização do conhecimento sobre o projeto de vida como uma construção difícil e complexa, remetendo-se às dificuldades: práticas institucionais, pressões sociais e construção de si mesmo na relação com o mundo, configurada pela maturidade/imaturidade e pela tomada de decisão acerca do projeto de vida e da carreira que se pretende seguir.

Quanto ao campo representacional, objetivase o projeto de vida nos dois grupos em imagens de desejos, metas, previsões e estratégias, sempre voltadas para a tríade educação/trabalho/família, bem como a imagem de inclusão social e melhoria de vida, elaborada por adolescentes em contexto escolar público, e a imagem de dificuldades na construção do projeto de vida, elaborada pelos adolescentes em contexto de escola privada. Verificou-se que os adolescentes são favoráveis à construção do projeto de vida, configurando-o como algo essencial ao longo da vida. Nos adolescentes em contexto de escola pública, emerge também uma aproximação positiva na elaboração do projeto de vida como uma possibilidade de inclusão social e melhoria de vida, embora dentro desse mesmo campo contextual se apreendam as impossibilidades dessa construção. Já no grupo de adolescentes em contexto de escola privada, emergem atitudes/afetos negativos na construção do projeto de vida em termos de dificuldades de sua construção.

Dessa maneira, esta pesquisa corrobora estudos anteriores realizados por Catão (2001a, 2001b, 2007) sobre as representações sociais na construção do projeto de vida por grupos em processo de exclusão, no que se refere à construção do projeto de vida como possibilidade de inclusão social 
configurado na tríade trabalho, educação e família e nas possibilidades/impossibilidades de construção do referido projeto. Como também já analisado pela referida autora nos estudos mencionados, observou-se na pesquisa em epigrafe que não é apenas a vontade pessoal e nem as circunstâncias que fundamentam o projeto, não é o indivíduo com suas características individuais ou a sociedade com suas determinações que, separadamente, constroem esse projeto, mas a relação de indissociabilidade entre todos esses fenômenos. É na relação indivíduo/ sociedade que se dá a construção do projeto de vida, na qual o indivíduo interage com o mundo e a alteridade, num processo contínuo e dinâmico de reconstrução das representações sociais.

Entende-se, assim, que o referencial teórico construído neste estudo poderá propiciar um conhecimento sobre o que os adolescentes nos contextos escolares público e privado pensam em relação às suas escolhas, sua história, seu comportamento e sua relação com as próprias instituições. Este estudo não esgota a possibilidade de futuros estudos com essa temática. No entanto, espera-se que ele possa contribuir para a formulação de novos questionamentos acerca da teoria das representações sociais e da construção do projeto de vida. Além disso, pensamos que os resultados desta pesquisa podem provocar reflexões e indicações para a formulação de políticas públicas, configurações de cultura da inclusão social e cidadania e práticas institucionais que possibilitem, nesses diferentes contextos escolares, condições que favoreçam a construção de projetos de vida dos adolescentes. 


\section{Maria Quitéria dos Santos Marcelino*}

Doutoranda em Psicologia social - Universidade Federal da Paraíba (UFPB).

\section{Maria de Fátima Fernandes Martins Catão}

Pós-Doutora em Psicologia social pela Pontifícia Universidade Católica de São Paulo PUC-SP, professora pesquisadora do departamento de psicologia e do programa de pós-graduação em psicologia social da Universidade Federal da Paraíba (UFPB).

E-mail: fathimacatao@uol.com.br

\section{Claudia Maria Pereira de Lima}

Graduada em Psicologia pela Universidade Federal da Paraíba (UFPB).

E-mail: claudinhampl@hotmail.com

\section{*Endereço para envio de correspondência:}

Rua Luiz Gonzaga, n 166 Bairro Perpétuo Socorro - Paulo Afonso - BA - Brasil, CEP: 48603-050

E-mail: mqmarcellino@yahoo.com.br

Recebido 03/07/2008 Reformulado 06/01/2009 Aprovado 14/01/2009

\section{Referencias}

Bardin, L. (2002). Análise de conteúdo. Paris: Presses Universitaires de France.

Bock, A. M. F., Furtado, O., \& Teixeira, M. L. (1996). Psicologias: uma introdução ao estudo de Psicologia. São Paulo: Saraiva.

Bock, A. M. F., Marchina, M. G. F., \& Furtado, O. (2001). Psicologia sócio-histórica: uma perspectiva crítica em psicologia. São Paulo: Cortez.

Castoriadis, C. (1985). A instituição imaginária da sociedade. Rio de Janeiro: Paz e Terra.

Catão, M. F. (2001a). Excluídos sociais em espaço de reclusão: representações sociais na construção do projeto de vida. Tese de Doutorado, Universidade de São Paulo, São Paulo.

Catão, M. F. (2001b). Projeto de vida em construção na exclusão/inserção social. João Pessoa: Ed. Universitária.

Catão, M. F. (2007). O que as pessoas pensam da vida e o que desejam nela realizar? In E. Kruttzen \& S. Vieira (Orgs.), Psicologia social, clínica e saúde mental (pp. 75-94). João Pessoa: Ed. Universitária.

Catão, M. F., \& Coutinho, M. P. (2003). Representações sociais: entre o indivíduo e a sociedade. In M. P. Coutinho, A. S. Lima, M. L. Fortunato, \& F. B. Oliveira (Orgs.), Representações sociais: interdisciplinar (pp. 184-193). João Pessoa: Ed. Universitária.

Clímaco, A. A. de S. (1991). Repensando as concepções da adolescência. Dissertação de Mestrado. Curso de pós Graduação em Psicologia da Educação, Pontifícia Universidade Católica de São Paulo, São Paulo.

Franco, L. A. C. (1991). A escola do trabalho e o trabalho da escola (3a ed.). São Paulo: Cortez.

Lourau, R., \& Ardoino, J. (1994). Les pédagogies institucionelles. Paris: PUF.
Jodelet, D. (2001). Representações sociais: um domínio em expansão. In D. Jodelet (Org.), As representações sociais. Rio de Janeiro: Ed. UERJ.

Moscovici, S. (1961). La psychanalyse: Son image et son public. Paris: Presses Universitaires de France.

Moscovici, S. (1984). Psicologie sociale. Paris: PUF

Moscovici, S. (2003). Representações sociais: investigações em psicologia social. Petrópolis, RJ: Vozes.

Ozella, S. (2002). Adolescência: uma perspectiva crítica. In M. L. J. Contini, S. H. Koller, \& M. N. S. Barros (Orgs.), Adolescência e psicologia: concepções, práticas e reflexões críticas. Brasília, DF: Conselho Federal de Psicologia.

Reinert, M. (1997). Introdução ao Alceste 4.O. (L. Faísca, trad.). Lisboa: Alceste.

Serrão, M., \& Baleeiro, M. C. (1999). Aprendendo a ser e a conviver (2a ed.). São Paulo: FTD.

Sawaia, B. (2006). Introduzindo a afetividade na reflexão sobre estética, imaginação e constituição do sujeito. In K. A. Maheirie, V. Zanella, \& S. Z. da Ros (Orgs.), Relações estéticas, atividade criadora e imaginação: sujeitos e (em) experiência (pp. 85-94). Florianópolis: Núcleo de Publicações da UFSC.

Vala, J. (1994). Análise conteúdo. In A. Silva \& J. Pinto (Orgs.), Metodologia em ciências sociais. Porto, Portugal: Apontamentos.

Vigotski, L. S. (1999). A formação social da mente. São Paulo: Martins Fontes.

Vigotski, L. S. (2000). A construção do pensamento e da linguagem. São Paulo: Martins Fontes. 